Title:

Advanced Tunable Laser Source for DoD Applications

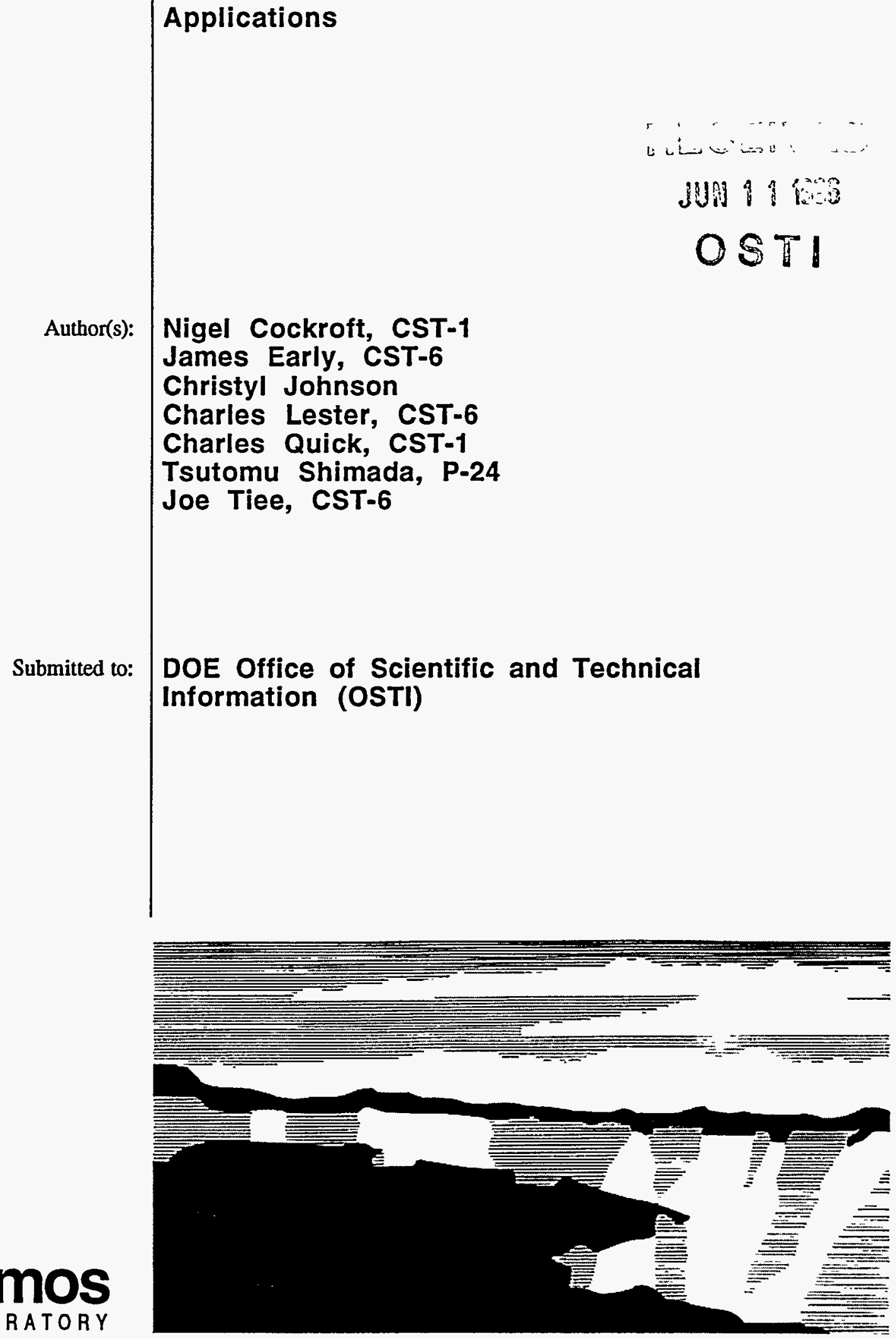

NATIONAL LABORATORY

Los Alamos Nallonal Laboratory, an afitmatlve action/equal opportunity employer, is operated by the University of Callomia for the U.S. Department of Energy under contract W-7405-ENG-36. By accoplance of this article, the publisher recognizes that the U.S. Govemment retains a nonexclustve, royaltytree license to publish or reproduce the published form of this contribution, or to allow others to do so, for U.S. Government purposes. The Los Alamos Natlonal Laboratory requests that the publisher ldentify this article as work performed under the auspices of the U.S. Department of Energy.

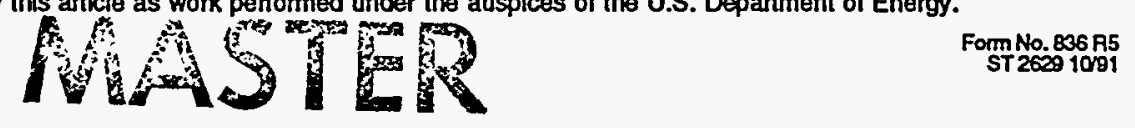




\title{
Advanced Tunable Laser Source for DoD Applications
}

\author{
Nigel Cockroft*, James Early, Christyl Johnson, Charles Lester, Charles Quick, \\ Tsutomu Shimada, and Joe Tiee
}

\begin{abstract}
This is the final report of a two-year, Laboratory-Directed Research and Development (LDRD) project at the Los Alamos National Laboratory (LANL). The project sought to develop a new solid-state laser transmitter that can be tuned over an exceptionally broad spectral range and integrated with LIDAR remote-sensing systems for applications in species-specific chemical sensing. Activities have included non-linear frequency conversion of tunable chromiumdoped LiSAF laser radiation to the ultra-violet and infrared spectral regions. This system is capable of the detection of chemical species previously unapproachable, as well as an improvement in detection sensitivity of 1-2 orders of magnitude for species currently studied.
\end{abstract}

\section{Background and Research Objectives}

Los Alamos has made many major contributions to the field of laser-based light detection and ranging (LIDAR) technology during the last twenty years. However, most of the current international LIDAR activity, including that occurring within the DOE complex, utilizes commercially available lasers that operate at a single fixed wavelength. Major advances in the application of LIDAR to DOE, DoD and civilian problems depends upon the development of new types of compact and efficient solid-state lasers. The objective of this project was to develop and configure a new type of broadly tunable laser specifically for LIDAR applications. Chromium-doped lithium strontium aluminum fluoride (Cr:LiSAF), which lases from $0.75 \mu \mathrm{m}$ to $1.0 \mu \mathrm{m}$, is the most exciting new prospect for such a laser. Unlike other potential candidates this material has a long-storage lifetime for efficient pulsed operation and has very strong absorption in the red, blue and UV regions that enables both flash lamp and diode-laser excitation. The latter characteristic optimizes the value of investment in Cr:LiSAF technology.

The specific research objectives of this project included characterization of optical gain, pumping efficiency, energy extraction, Q-switching and tuning mechanisms for Cr:LiSAF. Goals included the demonstration of a narrow spectral bandwidth laser with 20-40 nsec pulses

*Principal investigator, e-mail: cockroft@lanl.gov 
of 0.3-2 Joule energy at approximately $20 \mathrm{~Hz}$ and its application to new DIAL LIDAR demonstrations.

\section{Importance to LANL's Science and Technology Base and National R\&D Needs}

During the last twenty-four years Los Alamos has been the major participant in more than twenty LIDAR experiments and has fielded numerous experimental LIDAR systems, four of which are currently operational. This project, which enhances the lasers available to LIDAR, therefore makes a direct and significant contribution to the LANL technology base. The project supports a Los Alamos core competency in earth and environmental systems. DOE needs that are expected to be addressed by this project include possible application to the advanced stages of the CALIOPE non-proliferation program and environmental monitoring applications within the DOE complex.

The development of this technology contributes directly to the research needs of the United States. Used in conjunction with frequency-doubling and-tripling techniques, LiSAF lasers are capable of continuously spanning the wavelength ranges from 250 to $333 \mathrm{~nm}, 375$ to $500 \mathrm{~nm}$, and 750 to $1000 \mathrm{~nm}$. The wavelengths of interest for CRDEC's Chemical and Biological Agent Detection Project (280 - $350 \mathrm{~nm}$ ), ARPA's Laser Verification Project (300 $350 \mathrm{~nm}$ ), a wide variety of NASA space-based LIDAR applications (UV through IR), envisioned and existing counter narcotics applications (approximately $300 \mathrm{~nm}$ ), measurement of common atmospheric constituents and pollutants $(350-400 \mathrm{~nm})$, oil slick detection and measurement (400 - $500 \mathrm{~nm}$ ), and Distributed Surveillance, Nonproliferation, and Global Warming Programs $(215-671 \mathrm{~nm})$ are roughly within these ranges. The LiSAF lasers are sufficiently flexible to eliminate unique laser developments for each LIDAR application. In addition, LiSAF lasers are likely to be the least expensive, most compact, and most platformcompatible options for a wide variety of non-LIDAR programs.

\section{Scientific Approach and Results to Date}

As many laser applications require high-pulse energy at moderate cost, we have chosen to explore fully the optimization of flash lamp, rather than diode-laser, excitation. We believe this to be the first time that such a system has been designed from "the-bottom-up" for LIDAR applications. The activities of this project have included materials evaluation such as comprehensive optical gain and loss measurements, optimization of the chromium-dopant level, thermal lensing characterization and optical- and thermal-damage characterization. This 
knowledge has been applied to the design and implementation of a prototype laser that has been very successfully used for LIDAR studies.

The Cr:LiSAF lasing results of the project have included demonstration of record average power $(16 \mathrm{~W})$, record Q-switched energy $(450 \mathrm{~mJ}$ ), record pulse repetition rate (40 $\mathrm{Hz}$ ), record Q-switching efficiency (85\% of free-run energy), record narrow-line width operation $(2 \mathrm{GHz})$ and record efficiency $(>7 \%)$. The project has enabled the characterization of several alternative cavity configurations and tuning mechanisms.

An emphasis has been placed on determining the operating characteristics of the laser that are most relevant to advanced differential absorption LIDAR (DIAL) techniques. This includes the development of good beam quality with continuous tunability and a narrow spectral line width. Tuning techniques included birefringent tuning plates with an intra-cavity telescope/iris combination, injection-seeding using tunable diode lasers (for the first time) and the use of a Littman grating tuning technique (for the first time). The latter proved particularly successful and enabled automation, using motors and piezo-electric drivers, of the laser's wavelength. Frequency doubling, tripling and quadrupling of the laser output to the blue and UV spectral regions was also achieved. During FY 1995 we demonstrated, for the first time, considerable improvements in the performance of LiSAF lasers by using a double laser rod configuration. A highlight of the year was the experimental integration at LANL of our dualrod system with a diode-pumped oscillator assembled by researchers from NASA Langley Research Center. During these experiments we demonstrated a record signal gain factor of 120 for a double pass.

The first LIDAR experiments using LiSAF were performed at Los Alamos in January, 1994. Using the LANL miniature LIDAR receiver, clouds were detectable by elastic back scatter at a range greater than $20 \mathrm{~km}$. Water vapor DIAL measurements were performed which showed substantial attenuation of the return for resonance wavelengths. After substantial laser modification further LIDAR experiments were performed in August/September, 1994. High quality DIAL measurements including the scanning of the laser over several atmospheric absorption bands were performed. These results were reported at the 1994 and 1995 Advanced Solid State Laser conferences. At the 1995 meeting the work was presented as the first technical paper of the conference. This data has formed the basis of several new program development activities. Differential fluorescence measurements of uranium ions excited in the blue region were demonstrated for the first time. LIDAR demonstrations were performed using the hybrid NASA/LANL laser to evaluate the feasibility of obtaining humidity and temperature profiles of the atmosphere. 


\section{Publications}

Shimada, Tsutomi; Early, James; and Cockroft, Nigel, "Repetitively-Pulsed Cr:LiSAF Laser for LIDAR Applications," in Proceedings of the OSA Advanced Solid State Lasers Meeting,
1994, LA-UR \#94-526.

Shimada, Tsutomu; Early, James; Lester, Charles; Quick, Charles; Tiee, Joe; and Cockroft, Nigel, "Continuously-Tunable, Narrow-Linewidth, q-Switched Cr:LiSAF Laser for Lidar Applications," in Proceedings of Advanced Solid-State Laser Meeting, 1995, LA-UR \#95-406.

\section{DISCLAIMER}

This report was prepared as an account of work sponsored by an agency of the United States Government. Neither the United States Government nor any agency thereof, nor any of their employees, makes any warranty, express or implied, or assumes any legal liability or responsibility for the accuracy, completeness, or usefulness of any information, apparatus, product, or process disclosed, or represents that its use would not infringe privately owned rights. Reference herein to any specific commercial product, process, or service by trade name, trademark, manufacturer, or otherwise does not necessarily constitute or imply its endorsement, recommendation, or favoring by the United States Government or any agency thereof. The views and opinions of authors expressed herein do not necessarily state or reflect those of the United States Government or any agency thereof. 